\title{
Utility of Routine Outpatient Cervical Spine Imaging Following Anterior Cervical Corpectomy and Fusion
}

Atman Desai ${ }^{1}$, Arjun V. Pendharkar ${ }^{1}$, Jessica G. Swienckowski ${ }^{2}$, Perry A. Ball ${ }^{2}$, Scott Lollis 2 Nathan E. Simmons ${ }^{2}$

1. Department of Neurosurgery, Stanford University School of Medicine 2. Section of Neurosurgery, Dartmouth-Hitchcock Medical Center

$\square$ Corresponding author: Arjun V. Pendharkar, apendhar@stanford.edu Disclosures can be found in Additional Information at the end of the article

\section{Abstract}

Background: Construct failure is an uncommon but well-recognized complication following anterior cervical corpectomy and fusion (ACCF). In order to screen for these complications, many centers routinely image patients at outpatient visits following surgery. There remains, however, little data on the utility of such imaging.

Methods: The electronic medical record of all patients undergoing anterior cervical corpectomy and fusion at Dartmouth-Hitchcock Medical Center between 2004 and 2009 were reviewed. All patients had routine cervical spine radiographs performed perioperatively. Follow-up visits up to two years postoperatively were analyzed.

Results: Sixty-five patients (mean age 52.2) underwent surgery during the time period. Eighteen patients were female. Forty patients had surgery performed for spondylosis, 20 for trauma, three for tumor, and two for infection. Forty-three patients underwent one-level corpectomy, 20 underwent two-level corpectomy, and two underwent three-level corpectomy, using an allograft, autograft, or both. Sixty-two of the fusions were instrumented using a plate and 13 had posterior augmentation. Fifty-seven patients had follow-up with imaging at four to 12 weeks following surgery, 54 with plain radiographs, two with CT scans, and one with an MRI scan. Unexpected findings were noted in six cases. One of those patients, found to have asymptomatic recurrent kyphosis following a two-level corpectomy, had repeat surgery because of those findings. Only one further patient was found to have abnormal imaging up to two years, and this patient required no further intervention.

Received 10/04/2015

Review began 10/29/2015

Review ended 11/11/2015

Published 11/23/2015

\section{@ Copyright 2015}

Desai et al. This is an open access article distributed under the terms of the Creative Commons Attribution License CC-BY 3.0., which permits unrestricted use, distribution, and reproduction in any medium, provided the original author and source are credited.
Conclusions: Routine imaging after ACCF can demonstrate asymptomatic occurrences of clinically significant instrument failure. In 43 consecutive single-level ACCF however, routine imaging did not change management, even when an abnormality was discovered. This may suggest a limited role for routine imaging after ACCF in longer constructs involving multiple levels.

Categories: Radiology, Neurosurgery, Orthopedics

Keywords: corpectomy, outpatient, radiograph, follow-up

\section{Introduction}

Anterior cervical corpectomy and fusion (ACCF) is a relatively common procedure that may be 
performed for a range of indications, including spondylotic myelopathy or radiculopathy, trauma, infection, or tumor [1-5]. Routine postoperative radiographs are often obtained after this procedure, exposing patients to radiation and adding to the overall costs; yet, there are few data to support this practice. Previous studies have suggested that for anterior cervical discectomy and fusion (ACDF) performed for cervical spondylosis, routine postoperative radiographs in asymptomatic patients may not be warranted [6-7].

Cervical corpectomy, however, is a more complex procedure than ACDF, with increased stress often placed upon the arthrodesis and supporting instrumentation [8]. Some studies have reported an increased rate of graft displacement and pseudoarthrosis after ACCF when compared to ACDF [9-10]. Furthermore, ACCF may often be augmented with posterior stabilization involving long instrumented constructs. These factors suggest that ACCF, in theory, may warrant increased postoperative surveillance [11]. In addition, smoking, steroid use, previous cervical spine surgery, previous pseudoarthrosis, pre-existing deformity, and the indication for surgery may all influence the decision to obtain routine imaging [12-15].

While the above factors may, in theory, increase the risk of detecting construct failure, the actual utility of routine imaging also relates to its influence upon subsequent management. As such, it is also unclear how often unexpected findings on routine imaging after ACCF, in fact, lead to changes in management. The purpose of this study was to evaluate the utility of obtaining routine static $\mathrm{x}$-rays after single or multiple level ACCFs are performed for a range of indications.

\section{Materials And Methods}

A retrospective analysis of the electronic medical record of all patients undergoing ACCF in our department from 2004-2009 was performed. Institutional Review Board approval was obtained for this study. Informed patient consent was obtained at the time of treatment. Patients undergoing a single or multilevel anterior cervical corpectomy, using a fibular allograft and/or iliac crest autograft, with or without a ventral cervical plate, with or without posterior augmentation, were all included in the study. All patients had postoperative radiographs within 24 hours of surgery and had routine clinical outpatient follow-up with further imaging scheduled for four to 12 weeks and thereafter on an as-needed basis, or per the surgeon's typical follow-up pattern. Patient follow-up up to two years was analyzed.

The medical record was reviewed and patient baseline characteristics, operative detail, and postoperative course recorded. Baseline characteristics analyzed included patient age, sex, indications for surgery, preoperative smoking status, steroid use, and osteoporosis. Operative details included cervical levels and the number instrumented, type of graft used, and the presence of additional posterior fusion. Follow-up data reviewed included the use of postoperative steroids, outpatient appointment time from surgery, clinical findings, and radiographic findings. Where unexpected radiographic findings were noted, we also recorded whether or not the patient underwent any change in therapeutic management as a result of the findings.

\section{Results}

\section{Baseline characteristics}

Sixty-five patients aged between 16 and 83 (mean 52.2, median 51) underwent surgery between 2004 and 2009 (Table 1). Eighteen patients were female. Ten patients were current smokers at the time of surgery, three patients had a history of previous cervical spine surgery, and one had a history of pseudoarthrosis. Six patients had preoperative kyphosis and seven patients had preoperative listhesis. Forty patients had surgery performed for spondylosis, 20 for trauma, 


\section{Cureus}

three for tumor, and two for infection. Forty-three patients presented with myelopathy, 34 patients with radiculopathy, and 33 with axial neck pain.

\section{Baseline Characteristics}

Mean (median) Age

Sex (female)

Smoking

Previous cervical spine surgery

Preoperative kyphosis

Preoperative listhesis

Pathology

Degenerative

Trauma

Tumor

Infection

Clinical complaint

Myelopathy

Radiculopathy

Axial neck pain

\section{Number of Patients}

$52.2(51)$

18

10

3

6

7

40

20

3

2

43

34

33

\section{TABLE 1: Baseline characteristics of patients undergoing ACCF}

\section{Surgical details}

Forty-three patients underwent one-level corpectomy, 20 underwent two-level, and two underwent three-level corpectomy (Table 2). Fifty-three patients had a fusion using a fibular allograft, four using an iliac crest autograft, and eight using both fibular allograft and iliac crest autograft. Sixty-two of the fusions were instrumented using a plate, and 13 had additional posterior augmentation with lateral mass screws or interspinous wiring. All of the patients underwent plain x-rays within 24 hours of surgery. There were no abnormal findings in any of these radiographs. 


\section{Cureus}

\begin{tabular}{|l|ll|}
\hline Number of Corpectomy Levels Performed & Number of Patients & Cervical Level (Numbers) \\
\hline One-level & 43 & C4 (7); C5 (15); C6 (16); C7 (5) \\
Two-level & 20 & C4+5 (8); C5+C6 (11); C6+C7 (1) \\
Three-level & 2 & C4+C5+C6 (2) \\
\hline
\end{tabular}

TABLE 2: Number of levels and cervical levels operated upon

\section{Follow-up and imaging findings}

Eight patients were lost to follow-up. Fifty-seven patients had follow-up with imaging at four to six weeks postoperatively and further follow-ups at the surgeon's discretion. Mean follow-up was 10.3 months. Eight patients were put on a course of postoperative steroids.

At the routine appointments at four to 12 weeks, 54 patients were imaged with x-rays, two patients with CT scans, and one patient with an MRI scan to assess for resolving infection. Fifteen patients reported clinical complaints at the early visit, but none was explainable by abnormal imaging. Of the 43 patients having undergone one-level ACCF, 38 reported no symptoms. Among all 54 patients, unexpected findings were noted in six cases. All of these patients had undergone instrumented fusion. All had improved overall clinically from baseline when assessed at this visit, although one had developed a deltoid weakness. One patient required intervention because of abnormal findings; this involved asymptomatic recurrent kyphosis with screw pullout following a two-level corpectomy, which required anterior release and posterior fusion with lateral mass screws and interspinous wiring. The other five patients, one of whom was a smoker, were successfully managed with observation.

Between three months and two years, only one patient demonstrated abnormal imaging findings and this patient required no further intervention. Of the overall patient cohort, five patients underwent further cervical spine surgery over the two years, but only one (at three months) was a revision surgery as a result of the failure of the initial surgery (Table 3). 


\section{Cureus}

\begin{tabular}{|c|c|c|c|c|c|c|c|}
\hline Patient & Age/Sex & Indication & Surgery & $\begin{array}{l}\text { 4-12 } \\
\text { Week } \\
\text { Imaging }\end{array}$ & $\begin{array}{l}\text { Unexpected } \\
\text { Findings }\end{array}$ & $\begin{array}{l}\text { New } \\
\text { Symptoms }\end{array}$ & Management \\
\hline 1 & $52 \mathrm{M}$ & Degenerative & $\begin{array}{l}\text { C5-C6 } \\
\text { Allograft/autograft } \\
\text { +posterior fusion }\end{array}$ & XR & Kyphosis & None & Reoperation \\
\hline 2 & $48 \mathrm{~F}$ & Degenerative & C6 Allograft & XR & Screw pullout & $\begin{array}{l}\text { Deltoid } \\
\text { weakness }\end{array}$ & Observation \\
\hline 3 & $69 \mathrm{M}$ & Degenerative & C4-C5 Allograft & XR & $\begin{array}{l}\text { Screw pullout and } \\
\text { break, telescoping of } \\
\text { graft }\end{array}$ & None & Observation \\
\hline 4 & $62 \mathrm{M}$ & Degenerative & C4-C5 Allograft & XR & Screw pullout & None & Observation \\
\hline 5 & $64 \mathrm{M}$ & Degenerative & C6-C7 Allograft & XR & Screw pullout & None & Observation \\
\hline 6 & $47 \mathrm{M}$ & Tumor & $\begin{array}{l}\text { C4-C5 } \\
\text { Allograft/autograft }\end{array}$ & XR & Telescoping of graft & $\begin{array}{l}\text { Worsened } \\
\text { baseline } \\
\text { hoarseness }\end{array}$ & Observation \\
\hline
\end{tabular}

TABLE 3: Characteristics of patients with abnormal imaging at 4-12 week follow-up

\section{Discussion}

Routine imaging after ACCF is commonly obtained at outpatient follow-up visits in asymptomatic patients [16]. The rationale for this practice is usually to evaluate for instrument failure, graft placement, and fusion status. The results of our study suggest that this practice can identify asymptomatic instances of hardware failure up to two years but that this rarely leads to a change in management. No patients with a single-level ACCF in our study had a change in management as a result of unexpected findings of instrument failure on routine imaging, and only one patient with a multi-level ACCF, in whom a recurrent asymptomatic kyphosis was found, required operative management. In addition, no patients with a history of smoking, steroid use, previous pseudoarthrosis, or surgery for trauma, infection, or neoplasm had routine imaging necessitating operative management.

The above results would suggest a limited role for routine imaging after ACCF. A previous study by Ugokwe, et al. [7] suggested that routine imaging after a single-level ACDF for degenerative disease was likely unwarranted and that significant instrumentation failure requiring intervention would be symptomatic. A more recent study by Shau, et al. [17] attempted to analyze the utility of postoperative radiographs in cervical spine fusion and found that in 140 postoperative outpatient visits for 43 patients following ACCF, none had imaging findings in clinic necessitating operative management, although the number of corpectomy levels was not reported. They also found no significant difference in the propensity for clinically significant abnormal imaging based on the surgical indication. ACCF comprises a more complex surgical procedure than single-level ACDF, with potentially greater stresses placed upon the construct and, therefore, increased likelihood of instrument failure. This likelihood may also in theory be affected by indication for surgery (e.g. trauma) and factors such as previous surgery, posterior instrumentation, smoking, and steroid use [11-15]. Our study found, however, that no patients following one-level ACCF had imaging findings requiring intervention regardless of the 
indication for surgery and also when the above factors were present. In our study, one patient, following a two-level corpectomy, was found to have an asymptomatic return of kyphosis on routine $\mathrm{x}$-ray and required reoperation, suggesting that routine imaging may have a greater role for surveillance of larger constructs.

Delivering quality in surgical care depends upon achieving good outcomes in a cost-effective manner. Central to this is the avoidance of unnecessary diagnostic or therapeutic procedures that expose patients to risk and add to overall cost. In light of this, several recent studies have attempted to address the utility of routine imaging after cervical spinal instrumentation and have tended to conclude that imaging may be best reserved for those patients who are symptomatic [6-7, 17]. Our own findings would support this recommendation in single-level ACCF, where those occasions with abnormal imaging were apparently not clinically significant and did not require a change in management. The patient in our series, however, who had undergone a multilevel corpectomy and in whom an asymptomatic kyphosis requiring reoperation was discovered on routine imaging may be part of a patient subset with longer constructs that would be an exception to such a rule. In essence, however, avoiding $\mathrm{x}$-rays on the 38 out of 43 patients in our series who were asymptomatic would, in addition to avoiding exposure of patients to unnecessary radiation, have saved costs incurred by imaging, radiographic interpretation, and provider clinic visits.

The present study has several limitations that should be considered. It is retrospective in nature, with post hoc data collection and interpretation susceptible to bias. The study also represents the experience of a single institution, and it remains unclear whether these findings apply to other centers. In addition, the study size is relatively small and may be underpowered to detect a higher rate of abnormal radiographs that influenced management.

\section{Conclusions}

Routine imaging after ACCF can demonstrate asymptomatic instances of instrument failure. In forty-three consecutive single-level corpectomies, however, routine imaging did not change management, even when abnormalities were discovered. This may suggest a limited role for routine imaging after ACCF and encourage more judicious use.

\section{Additional Information}

\section{Disclosures}

Human subjects: Consent was obtained by all participants in this study. Animal subjects: All authors have confirmed that this study did not involve animal subjects or tissue. Conflicts of interest: In compliance with the ICMJE uniform disclosure form, all authors declare the following: Payment/services info: All authors have declared that no financial support was received from any organization for the submitted work. Financial relationships: All authors have declared that they have no financial relationships at present or within the previous three years with any organizations that might have an interest in the submitted work. Other relationships: All authors have declared that there are no other relationships or activities that could appear to have influenced the submitted work.

\section{References}

1. Bailey RW, Badgley CE: Stabilization of the cervical spine by anterior fusion . J Bone Joint Surg Am. 1960, 42:565-94.

2. Brown JA, Havel P, Ebraheim N, Greenblatt SH, Jackson WT: Cervical stabilization by plate and bone fusion. Spine (Phila Pa 1976). 1988, 13:236-40.

3. Emery SE, Bohlman HH, Bolesta MJ, Jones PK: Anterior cervical decompression and arthrodesis for the treatment of cervical spondylotic myelopathy. Two to seventeen-year 
follow-up. J Bone Joint Surg Am. 1998, 80:941-51.

4. Hilibrand AS, Fye MA, Emery SE, Palumbo MA, Bohlman HH: Increased rate of arthrodesis with strut grafting after multilevel anterior cervical decompression. Spine (Phila Pa 1976). 2002, 27:146-51. 10.1097/00007632-200201150-00005

5. Nirala AP, Husain M, Vatsal DK: A retrospective study of multiple interbody grafting and long segment strut grafting following multilevel anterior cervical decompression. Br J Neurosurg. 2004, 18:227-32. 10.1080/02688690410001732643

6. Bartels RH, Beems T, Schutte PJ, Verbeek AL: The rationale of postoperative radiographs after cervical anterior discectomy with stand-alone cage for radicular pain. J Neurosurg Spine. 2010, 12:275-79. 10.3171/2009.9.SPINE09263

7. Ugokwe KT, Kalfas IH, Mroz TE, Steinmetz MP: A review of the utility of obtaining repeated postoperative radiographs following single-level anterior cervical decompression, fusion, and plate placement. J Neurosurg Spine. 2008, 9:175-79. 10.3171/SPI/2008/9/8/175

8. Hussain M, Nassr A, Natarajan RN, An HS, Andersson GB: Corpectomy versus discectomy for the treatment of multilevel cervical spine pathology: a finite element model analysis. Spine J. 2012, 12:401-8. 10.1016/j.spinee.2012.03.025

9. Sasso RC, Ruggiero RA, Jr., Reilly TM, Hall PV: Early reconstruction failures after multilevel cervical corpectomy. Spine. 2003, 28:140-42. 10.1097/00007632-200301150-00009

10. Uribe JS, Sangala JR, Duckworth EA, Vale FL: Comparison between anterior cervical discectomy fusion and cervical corpectomy fusion using titanium cages for reconstruction: analysis of outcome and long-term follow-up. Eur Spine J. 2009, 18:654-62. 10.1007/s00586009-0897-9

11. Deen HG, Nottmeier EW, Reimer R: Early complications of posterior rod-screw fixation of thecervical and upper thoracic spine. Neurosurgery. 2006, 59:1062-67. 10.1227/01.NEU.0000245592.54204.D0

12. Lee C, Dorcil J, Radomisli TE: Nonunion of the spine: a review . Clin Orthop Relat Res. 2004, 419:71-75.

13. Steinmann JC, Herkowitz HN: Pseudarthrosis of the spine. Clin Orthop Relat Res. 1992, 284:80-90.

14. Wang MC, Chan L, Maiman DJ, Kreuter W, Deyo RA: Complications and mortality associated with cervical spine surgery for degenerative disease in the United States. Spine (Phila Pa 1976). 2007, 32:342-47. 10.1097/01.brs.0000254120.25411.ae

15. Yadla S, Malone J, Campbell PG, Nasser R, Maltenfort MG, Harrop JS, Sharan AD, Ratliff JK: Incidence of early complications in cervical spine surgery and relation to preoperative diagnosis: a single-center prospective study. J Spinal Disord Tech. 2011, 24:50-54. 10.1097/BSD.0b013e3181d0d0e8

16. Kim MK, Kim SM, Jeon KM, Kim TS: Radiographic Comparison of Four Anterior Fusion Methods in Two Level Cervical Disc Diseases : Autograft Plate Fixation versus Cage Plate Fixation versus Stand-Alone Cage Fusion versus Corpectomy and Plate Fixation. J Korean Neurosurg Soc. 2012, 51:135-40. 10.3340/jkns.2012.51.3.135

17. Shau DN, Bible JE, Samade R, Gadomski SP, Mushtaq B, Wallace A, McGirt MJ, O'Neill KR, Devin CJ: Utility of postoperative radiographs for cervical spine fusion: a comprehensive evaluation of operative technique, surgical indication, and duration since surgery. Spine (Phila Pa 1976). 2012, 37:1994-2000. 10.1097/BRS.0b013e31825c0130 